\title{
Study to evaluate association of umbilical coiling index and perinatal outcome
}

\author{
Deepika Chholak ${ }^{1}$, Pratiksha Gupta ${ }^{1 *}$, Santosh Khajotia ${ }^{2}$
}

\begin{abstract}
${ }^{1}$ Department of Obstetrics and Gynaecology, Post graduate Institute of Medical Sciences and Research, Basaidarapur, New Delhi, India

${ }^{2}$ Department of Obstetrics and Gynaecology, S. P. Bikaner Medical College, Bikaner, Rajasthan, India
\end{abstract}

Received: 28 December 2016

Accepted: 03 January 2017

\author{
*Correspondence: \\ Dr. Pratiksha Gupta, \\ E-mail: drpratiksha@gmail.com
}

Copyright: (c) the author(s), publisher and licensee Medip Academy. This is an open-access article distributed under the terms of the Creative Commons Attribution Non-Commercial License, which permits unrestricted non-commercial use, distribution, and reproduction in any medium, provided the original work is properly cited.

\section{ABSTRACT}

Background: To correlate the perinatal outcome by noting the umbilical coiling index.

Methods: The umbilical cords of the babies born to 500 women, who delivered either vaginally or by lower segment caesarean section, were examined and umbilical coiling index was calculated.

Results: There was significant correlation ( $p$ value 0.003 ) between. Hypercoiling (UCI >90th percentile) is associated with IUGR. Hypocoiling (UCI <10th percentile) is associated with: - Meconium staining liquor, high LSCS rates, low Apgar score $<7$ at $1 \mathrm{~min}$ and at 5 min respectively and NICU admissions of babies.

Conclusions: Hypercoiling (UCI >90th percentile) is associated with IUGR Hypocoiling (UCI <10th percentile) is associated with meconium staining liquor, high LSCS rates, low Apgar score $<7$ at $1 \mathrm{~min}$ and at 5 min respectively and NICU admissions of babies.

Keywords: Hypocoiling, Hypercoiling, Umbilical coiling index

\section{INTRODUCTION}

The umbilical cord or funis forms the connecting link between the fetus and the placenta. The umbilical cord is protected by Wharton's jelly, amniotic fluid, helical patterns, and coiling of vessels. ${ }^{1}$ The origin of umbilical cord coiling is unknown. The cause, role and mechanism of umbilical cord coiling have not been elucidated; nonetheless it has been shown that the coiling level is associated with adverse perinatal outcome such as intrauterine fetal death, intrauterine growth restriction and fetal distress during labor. ${ }^{2,3}$ A coil is defined as complete $360^{\circ}$ spiral courses of umbilical vessels around the Wharton's jelly. ${ }^{4}$ The number of twists seen in first trimester is roughly the same as that seen in term cords. The total number of coils seen is between 0 and 40 . Umbilical coiling appears to confer turgor to the umbilical unit, producing a cord that is strong, yet flexible. Since lengthening of the cord occurs from the fetal end, perhaps coiling of the cord represents a longterm record of fetal wellbeing. ${ }^{5-8}$ Strong et al. simplified by eliminating these directional scores and named it, "The umbilical coiling Index" (UCI) The UCI was calculated, by dividing the total number of coils by the total length of cord in centimeters. ${ }^{9}$

An abnormal UCI includes both hypocoiled cords (i.e.; cords with UCI <10th percentile) and hypercoiled cords (i.e.; cords with UCI >90th percentile). An abnormal UCI has been reported to be related to adverse perinatal outcome.

\section{METHODS}

The study was conducted in Department of Obstetrics and Gynaecology, in our Institutes during December 2011 to 
Jan 2014. In study population, 500 pregnant women with term gestation with singleton pregnancy, irrespective of their parity, admitted to the labour room were enrolled in the study.

\section{Inclusion criteria}

- Healthy women with term gestation irrespective of parity

- $\quad$ Singleton pregnancy

- Live baby

- Delivery both vaginal and LSCS

\section{Exclusion criteria}

- Multifetal gestation

- Anomalous foetus

- Single umbilical artery

- Pre-existing maternal diseases like Hypertension, Diabetes, and Chronic renal disease

- Smoking and Drug abuse

\section{Methodology}

Each woman was observed in second and third stage of labour. After separating the baby from the umbilical cord, the cord was tied and cut as close to placenta as possible. The umbilical cord was measured in its entirety, including the length of the placental end of the cord and the umbilical stump on the baby. The number of the complete coils or spirals were counted from the neonatal end towards the placental end of the cord and expressed in centimetres. The UCI was calculated, by dividing the total number of coils by the total length of cord in centimetres. UCI $=$ number of coils/Total length of cord in cms.
After calculating the UCI, perinatal factors like mode of delivery, meconium staining, fetal weight, Apgar score, all the women and babies, including babies admitted in NICU, were followed till discharge.

\section{RESULTS}

Among 500 women studied, 215(43\%) were booked and $285(57 \%)$ were unbooked. Multigravida was 105 , second gravida were 90 and primigravida were 305.250 women were in the age group of 21-25 years, while 173 (34.6\%) women delivered by LSCS, $327(65.4 \%)$ delivered vaginally. $395 \quad(79 \%)$ umbilical cords showed normocoiling, $54(10.8 \%)$ had hypocoiling and 51 (10.2\%) hypercoiling (Table 1). 141 babies, weighed $<2.5 \mathrm{~kg}$. Meconium staining liquor was present in $60(12 \%)$ cases, Apgar score at 1 min $<7$ was observed in 152 cases and $>7$ in 348 cases. Apgar score at 5 min was $<7$ in 155 cases and $>7$ in 345 cases.

According to mode of delivery, out of total 327 vaginal deliveries, 272 had their UCI within normal range, 28 and 27 females had their UCI hypo and hyper coiling respectively.

In all caesarian deliveries, out of total 173 females, 123 had their UCI within normal range while 26 and 24 females had hypo and hyper coiling respectively and this difference also found statistically significant $(\mathrm{p}<0.01)$. Out of total 333 females who had their babies birth weight $2.51-3.00 \mathrm{~kg}, 272$ females had their UCI within normal range while 33 and 28 females had hypo and hyper coiling respectively while females who had their babies birth weight $\leq 2.5 \mathrm{~kg} \mathrm{107,} 12$ and 22 females had their UCI normal, hypo and hyper coiling. On statistical analysis, the difference was found statistically highly significant $(\mathrm{p}<0.001)$ (Table 2).

Table 1: Correlation of mode of delivery with UCI.

\begin{tabular}{|c|c|c|c|c|c|c|c|c|}
\hline \multirow{2}{*}{ Mode of delivery } & \multicolumn{2}{|c|}{ Normal } & \multicolumn{2}{|c|}{ Hypo coiling } & \multicolumn{2}{|c|}{ Hyper coiling } & \multicolumn{2}{|c|}{ Total } \\
\hline & No. & $\%$ & No. & $\%$ & No. & $\%$ & No. & $\%$ \\
\hline LSCS & 123 & 31.1 & 26 & 48.1 & 24 & 47.1 & 173 & 34.6 \\
\hline Vaginal & 272 & 68.9 & 28 & 51.9 & 27 & 52.9 & 327 & 65.4 \\
\hline$\chi^{2}$ & 9.969 & & & & & & & \\
\hline$\frac{n}{\mathrm{P}}$ & 0.007 & & & & & & & \\
\hline
\end{tabular}

Table 2: Correlation of baby weight with UCI.

\begin{tabular}{|c|c|c|c|c|c|c|c|c|}
\hline \multirow{2}{*}{ Baby weight } & \multicolumn{2}{|l|}{ Normal } & \multicolumn{2}{|c|}{ Hypo coiling } & \multicolumn{2}{|c|}{ Hyper coiling } & \multicolumn{2}{|c|}{ Total } \\
\hline & No. & $\%$ & No. & $\%$ & No. & $\%$ & No. & $\%$ \\
\hline$\leq 2.5$ & 107 & 27.1 & 12 & 22.2 & 22 & 43.1 & 141 & 28.2 \\
\hline $2.51-3.50$ & 272 & 68.9 & 33 & 61.1 & 28 & 54.9 & 333 & 66.6 \\
\hline$>3.50$ & 16 & 4.1 & 9 & 16.7 & 1 & 2.0 & 26 & 5.2 \\
\hline$\chi^{2}$ & 22.174 & & & & & & & \\
\hline $\mathrm{P}$ & $<0.001$ & & & & & & & \\
\hline
\end{tabular}


Table 3: Correlation of IUGR with UCI.

\begin{tabular}{|c|c|c|c|c|c|c|c|c|}
\hline \multirow{2}{*}{ IUGR } & \multicolumn{2}{|c|}{ Normal } & \multicolumn{2}{|c|}{ Hypo coiling } & \multicolumn{2}{|c|}{ Hyper coiling } & \multicolumn{2}{|c|}{ Total } \\
\hline & No. & $\%$ & No. & $\%$ & No. & $\%$ & No. & $\%$ \\
\hline Yes & 1 & 0.2 & 0 & & 19 & 37.2 & 20 & 4 \\
\hline No & 394 & 98.8 & 54 & 100 & 32 & 62.8 & 480 & 96 \\
\hline$\chi^{2}$ & 42.5 & & & & & & & \\
\hline $\mathrm{P}$ & $<0.0$ & & & & & & & \\
\hline
\end{tabular}

Table 4: Correlation of meconium staining liquor with UCI.

\begin{tabular}{|lllllllll|}
\hline & Normal & \multicolumn{3}{c}{ Hypo coiling } & \multicolumn{3}{c|}{ Hyper coiling } & Total \\
\hline Mes & No. & $\%$ & No. & $\%$ & No. & $\%$ & No. & $\%$ \\
\hline No & 18 & 4.6 & 40 & 74 & 2 & 4 & 60 & 12 \\
\hline$\chi^{2}$ & 377 & 95.4 & 14 & 26 & 49 & 96 & 440 & 88 \\
\hline P & 42.543 & & & & & & \\
\end{tabular}

Table 5: Correlation of Apgar Score at 1 minute with UCI.

\begin{tabular}{|c|c|c|c|c|c|c|c|c|}
\hline \multirow{2}{*}{ Apgar Score $1 \mathrm{~min}$} & \multicolumn{2}{|c|}{ Normal } & \multicolumn{2}{|c|}{ Нypo coiling } & \multicolumn{2}{|c|}{ Hyper coiling } & \multicolumn{2}{|c|}{ Total } \\
\hline & No. & $\%$ & No. & $\%$ & No. & $\%$ & No. & $\%$ \\
\hline$\leq \underline{7}$ & 105 & 26.6 & 35 & 64.8 & 12 & 23.5 & 152 & 30.4 \\
\hline$\overline{>7}$ & 290 & 73.4 & 19 & 35.2 & 39 & 76.5 & 348 & 69.6 \\
\hline$\chi^{2}$ & 34.0 & & & & & & & \\
\hline $\mathrm{P}$ & $<0.0$ & & & & & & & \\
\hline
\end{tabular}

Table 6: Correlation of Apgar Score at 5 minute with UCI.

\begin{tabular}{|c|c|c|c|c|c|c|c|c|}
\hline \multirow{2}{*}{ Apgar Score $5 \mathrm{~min}$} & \multicolumn{2}{|c|}{ Normal } & \multicolumn{2}{|c|}{ Нypo Coiling } & \multicolumn{2}{|c|}{ Hyper coiling } & \multicolumn{2}{|c|}{ Total } \\
\hline & No. & $\%$ & No. & $\%$ & No. & $\%$ & No. & $\%$ \\
\hline$\leq 7$ & 107 & 27.1 & 36 & 66.7 & 12 & 23.5 & 155 & 31.0 \\
\hline$>7$ & 288 & 72.9 & 18 & 33.3 & 39 & 76.5 & 345 & 69.0 \\
\hline$\chi^{2}$ & 36.2 & & & & & & & \\
\hline $\mathrm{P}$ & $<0.0$ & & & & & & & \\
\hline
\end{tabular}

Out of 500 babies, 20 (4\%) had IUGR. Out of which 1 $(0.2 \%)$ had normocoiling, none had hypocoiling, 19 (37.2\%) had hypercoiling. 480 (96\%) babies didn't have IUGR. Out of which 394 (98.8\%) had normocoiling, 54 $(100 \%)$ had hypocoiling and $32(62.8 \%)$ had hypercoiling. $\mathrm{P}$ value being $<0.001(\mathrm{P}<0.01)$ is strongly significant. Hypercoiled cords are associated IUGR. (Table 3).

Out of 500 cases studied $60(12 \%)$ had meconium stained liquor. Out of which 18 (4.6\%) had normocoiling, 40 (74\%) had hypocoiling, 2 (4\%) had hypercoiling. 440 $(88.0 \%)$ cases did not have meconium stained liquor. Out of them 377 (95.4\%) had normocoiling, 14 (26\%) had hypocoiling and $49(96.0 \%)$ had hypercoiling, which was statistically strongly significant with $P$ value being $<0.001$ ( $\mathrm{P}<0.01)$ is strongly significant. Meconium staining is more in hypocoiled group (Table 4).
The correlation of Apgar score at 1 minute with UCI (Table 5). Out of total 348 patients who had their Apgar score >7 290 had normal UCI, 19 had hypo coiling while 39 had hyper coiling. In Apgar score $\leq 7$ at 1 minute, out of total 152 patients, 105 had normal UCI while 35 had hypo coiling and 12 patients had hyper coiling. On applying chi square test, the difference was found statistically highly significant $(\mathrm{p}<0.001)$.

Table 6 shows correlation of Apgar score at 5 minute with UCI. Out of total 345 patients who had their Apgar score > 7, 288 had normal UCI, 18 had hypo coiling while 39 had hyper coiling. In Apgar score $\leq 7$ at 5 minute, out of total 155 patients, 107 had normal UCI while 36 had hypo coiling and 12 patients had hyper coiling. On applying chi square test, the difference was found statistically highly significant $(\mathrm{p}<0.001)$. 
In present study, out of total 500 babies, only 156 babies required NICU admission and out of them 107 females had normal UCI while 37 females had hypo coiling and 12 females had hyper coiling. Out of total 344 babies who had not required NICU admission, 288 females had normal UCI, 17 had hypo coiling and 39 had hyper coiling. On statistical analysis, the difference was found highly significant $(\mathrm{p}<0.001)$ (Table 7).

Table 7: Correlation of NICU Admission with UCI.

\begin{tabular}{|c|c|c|c|c|c|c|c|c|}
\hline \multirow{2}{*}{ NICU admission } & \multicolumn{2}{|c|}{ Normal } & \multicolumn{2}{|c|}{ Hypo Coiling } & \multicolumn{2}{|c|}{ Hyper coiling } & \multicolumn{2}{|c|}{ Total } \\
\hline & No. & $\%$ & No. & $\%$ & No. & $\%$ & No. & $\%$ \\
\hline Yes & 107 & 27.1 & 37 & 68.5 & 12 & 23.5 & 156 & 31.2 \\
\hline No & 288 & 72.9 & 17 & 31.5 & 39 & 76.5 & 344 & 68.8 \\
\hline$\chi^{2}$ & 39.5 & & & & & & & \\
\hline $\mathrm{P}$ & $<0.0$ & & & & & & & \\
\hline
\end{tabular}

\section{DISCUSSION}

Several trials in the past have correlated the relationship between perinatal outcome and the UCI. In the present study, UCI was compared with various parameters. Comparing umbilical cord length to parity, it was found that there was no statistical significance between primi and multi and no statistical significance was observed when umbilical coiling was compared with either sex of baby and patient age. In present study, observation made that coiling of umbilical cords strongly associated with mode of delivery. Hypocoiled cords group were associated with more LSCS rates.

In present study it was observed that meconium staining was significantly associated with UCI <10th percentile. Gupta et al. studied 107 umbilical cords and found that in hypocoiling group, meconium staining was significantly higher than those with normal coiling group. ${ }^{4}$ Strong et al. studied 100 umbilical cords and found that meconium staining was associated with UCI values <10th percentile, with the $\mathrm{p}$ value of 0.03 which is highly significant. ${ }^{9}$ Padmanabhan et al. ${ }^{10}$ also conducted a study of 130 cases, where they found that meconium staining was significant among the hypocoiled group.

In present study, Apgar score $<7$ at $1 \mathrm{~min}$ and $5 \mathrm{~min}$ was found with UCI <10th percentile or hypocoiled cords. Gupta et al. and Padmanabhan et al. also found that hypocoiled group was associated with low Apgar score. ${ }^{4,10}$ Monique et al. also observed that hypocoiling was associated with low Apgar $<7$ at 5 min. ${ }^{11}$ This was explained by an experiment by Georgious et al. in which venous perfusion was measured in cords subjected to standardized tight encirclement force. ${ }^{12}$ A significant inverse relationship was found between coiling index and the minimum weight required to occlude venous perfusion. So, hypocoiling may give way to kinking and compression, whereas, hypercoiling may give way to occlusion in cases with cord entanglement. This may help to explain, the association with low Apgar score in hypocoiled cords. Gupta et al. studied 107 cords and found that babies with Apgar score $<7$ had significantly lower UCI than the babies with Apgar score $>7(0.05) .{ }^{10}$ Padmanabhan et al. studied 130 umbilical cords and found that hypocoiled group was associated with low Apgar $<7 .{ }^{10}$ Birth weight in relation to UCI was studied $28.2 \%$ had birth weight less than $2.5 \mathrm{Kg}$. Out of which $43.1 \%$ had hypercoiling, $27.1 \%$ had normocoiling and 22.2 had hypocoiling. $66.6 \%$ had birth weight between $2.5-3.5 \mathrm{Kg}$. $\mathrm{P}$ value being $<0.001$ is strongly significant. Hypercoiled group were associated with low birth weight. In the present study, $4 \%$ of babies had IUGR. Out of which $0.2 \%$ had normocoiling, none had hypocoiling, and $37.2 \%$ had hypercoiling. P value being $<0.001$ ( $\mathrm{P}<0.01)$ is strongly significant. Hypercoiled cords are associated IUGR. Monique et al. ${ }^{11}$ who studied 885 cases, found that hypocoiling was associated with small for gestational age infants. Georgiou et al. ${ }^{12}$ studied 34 cases and found that IUGR was found in hypercoiled group.

In present study, there was statistical significance about NICU admission and UCI. In the present study, $31.2 \%$ babies had NICU admission out of which $27.1 \%$ had normocoiling, $68.5 \%$ had hypocoiling, and $23.5 \%$ had hypercoiling. Whereas $69 \%$ didn't have NICU admission, of which $72.9 \%$ had normocoiling, $31.5 \%$ had hypocoiling, $76.5 \%$ had hypercoiling. $\mathrm{P}$ value being $<0.001$. Hypocoiled cords have more NICU admissions. Devaru D, Thusoo ${ }^{13}$ studied that hypocoiled cords or UCI $<10$ th percentile is associated with the meconium staining, Apgar score at $1 \mathrm{~min}<4$ and Apgar score at 5 min $<7$. The hypercoiled cord or UCI $>10$ th percentile is associated with intra uterine growth restriction. Monique et al. ${ }^{11}$ observed that hypocoiling of the cord was associated with fetal death. Similarly, Patil et $\mathrm{al}^{14}$ when they found hypercoiled cords or UCI which was >90th percentile was associated with IUGR and low ponderal indices. Hypocoiled cords was associated with meconium staining, low Apgar score at $1 \mathrm{~min}<4$ and at $5 \mathrm{~min}<7$, more LSCS rates and more NICU admissions. In the year 2007, de Laatet al did a study to evaluate umbilical cord coiling in pregnancies with adverse outcome. ${ }^{15}$ They observed that Fetal death, chorioamnionitis, fetal 
structural or chromosomal abnormalities, and lower Apgar score at $5 \min (\mathrm{p}=0.03)$ were associated with undercoiling. Fetal death, iatrogenic preterm delivery, umbilical arterial $\mathrm{pH}<7.05$, fetal structural or chromosomal abnormalities, thrombosis in fetal placental vessels, chronic fetal hypoxia/ischemia, and lower weight for gestational age $(\mathrm{p}=0.01)$ were associated with overcoiling. They concluded that adverse perinatal outcome is associated with both undercoiling and overcoiling of the umbilical cord. Chitra et $\mathrm{al}^{16}$ did a study to measure umbilical coiling index (UCI) postnatally and to study the association of normocoiling, hypocoiling and hypercoiling to maternal and perinatal outcome. The mean umbilical coiling index was found to be $0.24 \pm 0.09$. Hypocoiling $(<0.12)$ was found to be significantly associated with hypertensive disorders, abruptio placentae, preterm labour, oligohydramnios, and fetal heart rate abnormalities. Hypercoiling (>0.36) was found to be associated with diabetes mellitus, polyhydramnios, cesarean delivery, congenital anomalies, and respiratory distress of the new-born. They concluded that abnormal umbilical coiling index is associated with several antenatal and perinatal adverse features.

Funding: No funding sources

Conflict of interest: None declared

Ethical approval: The study was approved by the Institutional Ethics Committee

\section{REFERENCES}

1. Chaurasia BD, Agarwal BM. Helical structure of the human umbilical cord. Acta Anat (Basel). 1979;103:226-30.

2. Strong TH. Jarles DL. Vega JS. Umbilical coiling index. Am J Obstetric Gynecol. 1994;170:29-32.

3. Garry CF. Kenneth JL. Steven LB. John CH. Dwight JR. Catherine YS. Williams's obstetrics. 23rdedition.United states of America. McGraw Hill; 2010.

4. Gupta S, Faridi MMA, Krishnan J. Umbilical coiling Index. J Obstet Gynecol India. 2006;56:315-9.
5. Edmonds HW. The spiral twists of normal umbilical cords in twins and single stone. Am J Obstet Gynecol. 1954;67:102-20.

6. Strong TH, Jarles DL, Vega JS, Feldman DB. The umbilical coiling index. Am J Obst Gynecol Part I 1994;179(1):29-32.

7. Larco RV, Jones KL, Benirschke K. The umbilical cord twist: origin, directions and relevance. Am J Obstet Gynecol. 1987;1547(4):833-8.

8. Strong TH, Finberg HL, Mattox JH. Antepartum diagnosis of noncoiled umbilical cords. Am J Obstet Gynecol. 1994;170:1729-33.

9. Strong TH, Jones KL, Benirschke K. The umbilical cord twist: origin, directions, and relevance. Am J Obstet Gynecol. 1987;157:833-8.

10. Padmanabhan LD, Mhaskar R, Mhaskar A. Umbilical vascular coiling and the perinatal outcome. J Obstet Gynecol India. 2001;51:43-4.

11. Monique de Laat WM, Frank A, Bots M. Umbilical coiling index in normal and complicated pregnancies. Obstet Gynecol. 2006;107:1049-55.

12. Georgiou HM, Rice GE, Walker SP. The effect of vascular coiling on venous perfusion during experimental umbilical cord encirclement. Am J Obstet Gynecol. 2001;184:673-8.

13. Devaru D, Thusoo M. Umbilical coiling index and the perinatal outcome. J Obstet Gynecol India. 2012;62(1):43-6.

14. Patil NS, Kulkarni SR, Lohitashwa R. Umbilical cord coiling index and perinatal outcome. J Clin Diagn Res. 2013;7(8):1675-7.

15. de Laat MW, van Alderen ED, Franx A, Visser GH, Bots ML, Nikkels PG. The umbilical coiling index in complicated pregnancy. Eur J Obstet Gynecol Reprod Biol. 2007;130(1):66-72.

16. Chitra T, Sushanth YS, Raghavan S. Umbilical coiling index as a marker of perinatal outcome: an analytical study. Obstet Gynecol Int. 2012:213689.

Cite this article as: Chholak D, Gupta P, Khajotia S Study to evaluate association of umbilical coiling index and perinatal outcome. Int J Reprod Contracept Obstet Gynecol 2017;6:408-12. 